\title{
ACUTE ATROPHIC CHARCOT'S DISEASE OF BOTH HIPS
}

\author{
Report of a Case
}

\author{
C. S. Kirkham, Sheffield, England \\ From the Royal Infirmary, Sheffield
}

Acute atrophic Charcot's disease of the hip is not a common condition, and cases in which it is possible to demonstrate radiographically the rapidity of the destructive process are extremely rare.

Chitty (1939) reported a case in which there was complete loss of one femoral head from Charcot's disease five months after the patient had sustained a fracture of the pelvis. when both hips were seen to be normal radiographically.

The case now reported is one of Charcot's disease of both hips. The femoral head on one side is shown to have been completely absorbed in less than five months, with no history of precipitating injury.

\section{CASE REPORT}

The patient, a woman of sixty-four, gave a history that while walking in the house ten days before admission to hospital her left leg suddenly gave way and she fell to the ground, since when she had been unable to walk. Swelling of the whole leg commenced two days later, and gradually increased.

At no time was there pain in the leg, but there had been "pins and needles" in both legs for several years.

On examination, the whole of the left lower limb was swollen and oedematous, with most swelling in the thigh, where there was some reddening of the skin. The peripheral pulses were all present. The sense of touch in both legs was impaired, and there was loss of all pain sensation and of vibration sense. Knee and ankle jerks were absent in both legs. Examination of the eyes showed Argyll-Robertson pupils.

There was gross instability of the left hip, but movements were painless.

Radiographs showed complete destruction of the head of the left femur, with some calcification in the surrounding soft tissues (Fig. 1). The Wassermann reaction was positive.

A diagnosis of acute atrophic Charcot's disease was made. The swelling slowly subsided with rest in bed and the patient was discharged from the ward.

When she was seen three weeks later the swelling had completely disappeared and she was managing to walk with a stick, although she had a severe limp.

The patient was readmitted three months later with the history that three weeks previously her right leg had suddenly let her down, and she had been unable to walk since. At the same time the leg began to swell, and this swelling steadily increased.

On examination, the whole right lower limb was swollen and oedematous. The swelling had an inflammatory appearance, especially in the thigh, where some indurated areas were palpable and the skin was reddened (Fig. 2).

There was no change in the neurological signs, as compared with the previous examination.

The right hip now showed the same gross instability as the left, and again there was an abnormal range of painless movement.

Radiographs showed that the head of the right femur had been completely absorbed, and soft-tissue calcification was present around this joint also (Fig. 3). 


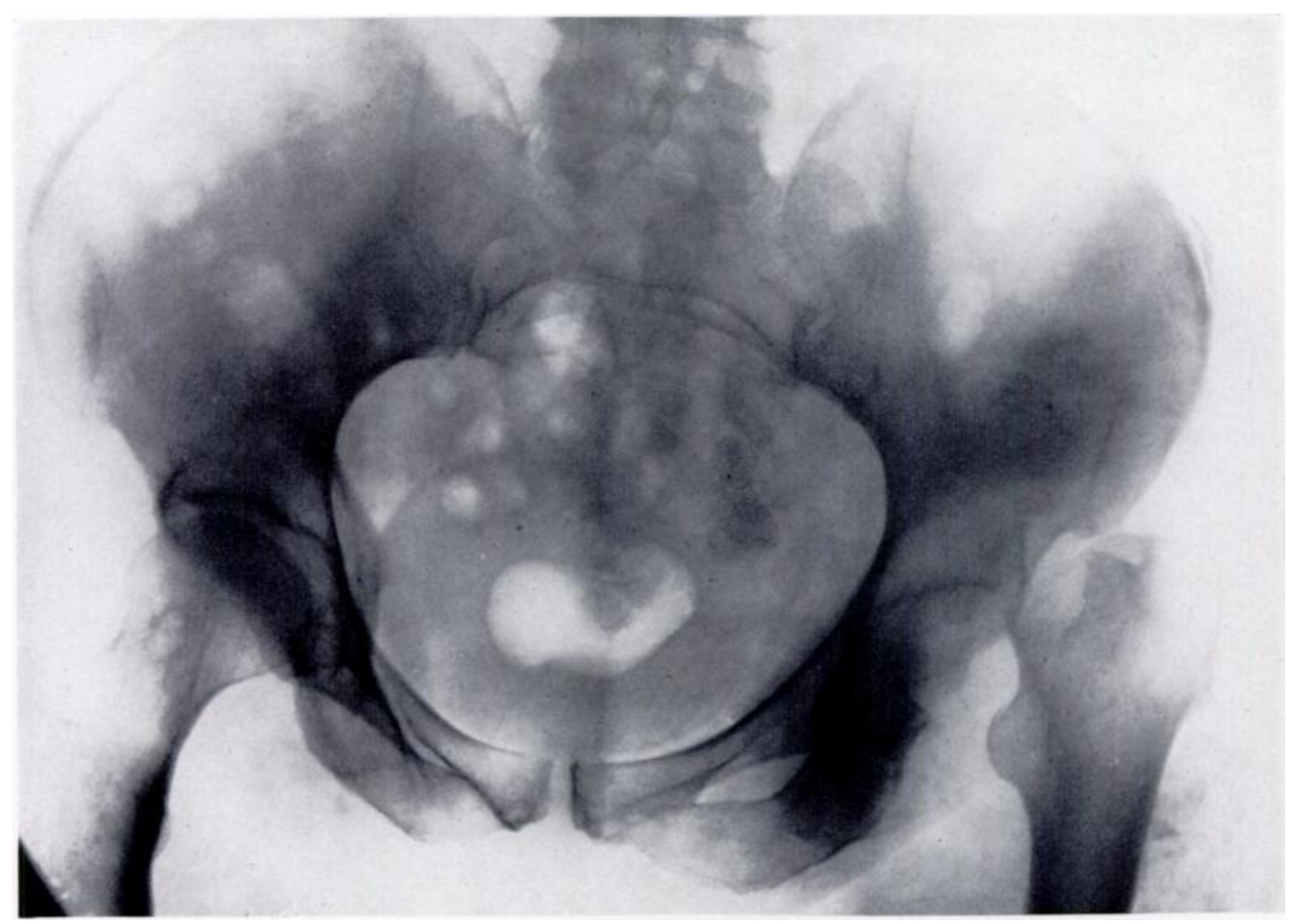

FIG. 1

Initial radiograph. Charcot's disease of left hip. Right hip unaffected.

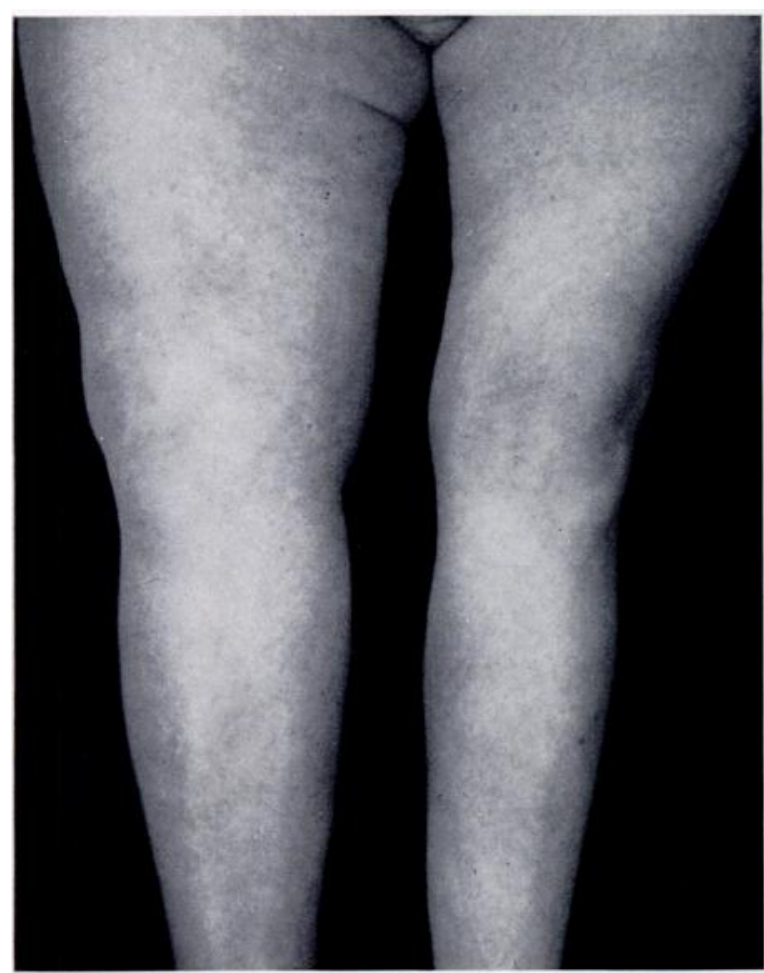

FIG. 2

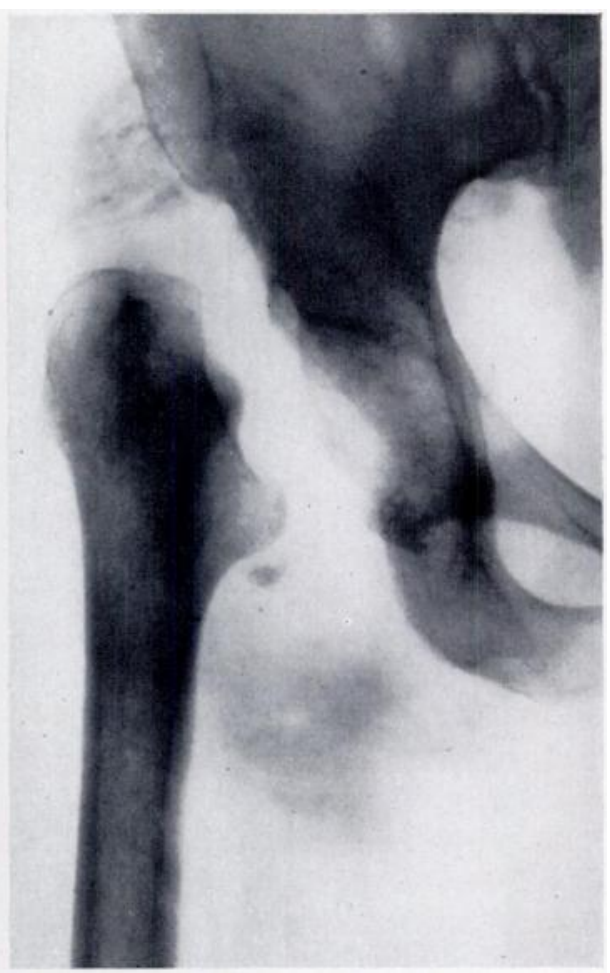

Fig. 3

Figure 2-Marked oedema of right lower limb complicating Charcot's disease of the hip. Figure 3-Radiograph of the right hip taken five months after that shown in Figure 1, showing destruction of the head and neck of VOL. 38 B, NO. 3, AUGUST 1956 the femur.

$\mathrm{I}-1_{14}$ 


\section{DISCUSSION}

The radiographs in this case show the typical appearances of atrophic Charcot's disease of the hips. The right femoral head was demonstrated to be normal at the time of the first admission, and less than five months later had been completely absorbed. There was no history of injury.

Another interesting feature of the case is the massive oedema of the whole limb. There was a similar swelling, confined to the thigh, in Chitty's case, and he suggested that the oedema around the joint was due to rupture of the joint capsule and liberation of a large quantity of synovial fluid into the soft tissues.

The history in the present case is consistent with this view, because in each leg the swelling commenced soon after the collapse of the affected joint, at which time the capsule probably ruptured. The local oedema around the joint may then interfere with the lymphatic and venous return from the leg, producing oedema of the whole leg and foot.

I wish to thank Mr F. W. Holdsworth for permission to publish this case.

\section{REFERENCE}

ChItry, H. (1939): Interesting Case of Charcot's Joint. British Journal of Surgery, 27, 183. 